(2) Open Access Full Text Article

\title{
An updated estimate of costs of endophthalmitis following cataract surgery among Medicare patients: 2010-2014
}

This article was published in the following Dove Press journal:

Clinical Ophthalmology

26 October 2016

Number of times this article has been viewed

\author{
Jordana K Schmier \\ Carolyn K Hulme-Lowe' \\ David W Covert ${ }^{2}$ \\ Edmund $\mathrm{C} \mathrm{Lau}{ }^{3}$ \\ 'Exponent, Inc., Health Sciences, \\ Alexandria, VA, ${ }^{2}$ Alcon Research \\ Ltd., Fort Worth, TX, ${ }^{3}$ Exponent, Inc., \\ Health Sciences, Menlo Park, CA, USA
}

Correspondence: Jordana K Schmier Exponent, Inc., I 800 Diagonal Rd., Suite 500, Alexandria, VA 223।4, USA $\mathrm{Tel}+\mid$ 57| 227 724|

Fax + I 57| 2277299

Email jschmier@exponent.com
Background: Endophthalmitis, which can occur after ophthalmic surgery, is an inflammation of the intraocular cavity and causes temporary or permanent vision impairment. However, little is known about the cost of treatment. The objective of this analysis was to update and expand upon the results of a previously published report that estimated the direct medical cost of treatment for endophthalmitis.

Methods: Retrospective data analysis using 2010 through 2014 United States Medicare Limited Data Sets. Procedure codes were used to identify beneficiaries who underwent cataract surgery; demographic and clinical characteristics at the time of diagnosis were determined. Patients were stratified into cases (those who developed endophthalmitis) and controls (those who did not develop endophthalmitis) in the 3 months following surgery. Claims (ie, charges) and reimbursements (ie, costs) for cases and controls in the 6 months following cataract surgery were identified and compared. Results are presented in 2015 US dollars.

Results: Of a total of 153,860 cataract surgery patients, 181 were diagnosed with endophthalmitis following cataract surgery, at a rate of 1.2 per 1,000. Cases were more likely to be male and less likely to be white than controls; age was similar. Total medical claims and reimbursements as well as ophthalmic claims and reimbursements were significantly higher for cases compared with controls. Total reimbursements, adjusted for age, sex, and region, were $\$ 4,893$ higher (83\% greater) and adjusted ophthalmic reimbursements were $\$ 3,002$ higher (156\% greater) for cases than for controls. Claims and reimbursements were significantly higher across all types of Medicare cost components.

Conclusion: Postcataract surgery endophthalmitis is associated with a substantial cost. Successful prophylaxis with antibiotic agents would reduce the significant costs associated with treating endophthalmitis.

Keywords: costs and cost analysis, endophthalmitis, eye infections, bacterial, health care costs

\section{Introduction}

Cataract surgery is common in the United States, with increasing rates among Medicare beneficiaries ${ }^{1}$ and anecdotal evidence suggesting that cataracts are increasingly treated among younger patients. Successful treatment is generally accepted as being costeffective and enhancing visual functioning, improving overall quality of life, and minimizing depression. ${ }^{2-4}$ However, cataract surgery is not without risk. Common complications include transient postoperative deterioration of visual acuity, ${ }^{5}$ and serious complications such as endophthalmitis, retinal detachment, or suprachoroidal hemorrhage can lead to more serious outcomes. ${ }^{6}$ Each of these risks and treatments carries with it potential long-term sequelae. Although uncommon, with $<1 \%$ of surgeries 
leading to serious complications, the impact of complications should be considered while estimating the overall impact and cost of illness. ${ }^{6}$

Postoperative endophthalmitis is an important concern following cataract surgery. ${ }^{7}$ The consequences of endophthalmitis can range from being minimal to requiring enucleation and are dependent on the causative agent, vision at the time of infection, and the type and timing of treatment. ${ }^{8-10}$ Patients with previous anti-VEGF treatment may have a higher risk of developing infection after surgery. ${ }^{11,12}$ Treatments for endophthalmitis are guided by culture and include intravitreal antibiotic injection, most frequently a combination of vancomycin with amikacin or with ceftazidime. ${ }^{13}$ Fluoroquinolones are also used with intravitreal antibiotics in severe cases, although they are not guideline-recommended. ${ }^{14}$ Vitrectomy may be used as an adjunct to therapy through better distribution of antibiotics but is usually considered only as a last resort when vision has deteriorated to light perception, and it is unlikely for intravitreal injection to be effective on its own. ${ }^{7,13}$

Not much is known about the total costs of treatment for endophthalmitis. There is evidence that postoperative endophthalmitis significantly increases hospitalization stay and $\operatorname{costs}^{15}$ and that outpatient treatment is less costly than inpatient treatment. ${ }^{16}$ The majority of cases in the United States, however, are not treated as inpatients. Our previous analysis of postcataract surgery endophthalmitis among Medicare beneficiaries using data from 1997 to 2001 found almost $\$ 3,500$ (in 2005 US dollars, $\sim \$ 4,780$ in 2015 US dollars) higher reimbursements for ophthalmic claims over 12 months among beneficiaries who developed the infection compared to those who did not. ${ }^{17}$

A recent study found that antibiotic prophylaxis can significantly reduce the rate of endophthalmitis. ${ }^{18,19}$ Based on the findings from the Endophthalmitis Vitrectomy Study (EVS), ${ }^{13}$ the American Academy of Ophthalmology now recommends prophylactic treatment with antibiotic agents for individuals undergoing ophthalmic surgery. ${ }^{20}$ Studies have even started to compare the cost-effectiveness among prophylactic treatments, with the underlying assumption that prophylaxis is economically defensible and the question is simply which treatment to offer. ${ }^{21-23}$

The objective of this study was to quantify recent 6-month direct medical costs associated with postoperative endophthalmitis among adults aged $\geq 65$ years in the United States. Although there has been a trend for cataract surgery among increasingly younger patients, as many as
$80 \%$ of cataract surgeries in the United States are performed on Medicare beneficiaries aged $\geq 65$ years, ${ }^{24}$ and Medicare will likely retain the most reimbursement responsibility for cataract surgery and subsequent complications in the United States. Thus, understanding the direct medical cost of this complication in the Medicare population represents an important step toward understanding the national impact.

\section{Methods}

Data were analyzed from 2010 through 2014 Medicare Limited Data Set (LDS) files. The LDS represents health care service claims from a systematic 5\% sample of all non-HMO Medicare enrollees and can be considered representative of US citizens aged $\geq 65$ years. The systematic $5 \%$ sample used for this claims data set is selected by the Centers for Medicare \& Medicaid Services (CMS) based on beneficiaries having certain digits in their health insurance ID; thus, the same patients are included in the LDS data each year (unless they die), with new patients meeting the selection criteria entering each year. The Medicare LDS data consist of seven claim components: Inpatient; Outpatient (covering ambulatory and outpatient care provided in a hospital facility); Durable Medical Equipment (DME); Hospice; Home Health Agency; Skilled Nursing Facility; and Physician/Supplier (Part B, covering outpatient care not provided in hospitals as well as physical and occupational therapy) claims. The LDS data were treated with appropriate integrity, security, and confidentiality, as detailed in the Data Use Agreement required by CMS.

For this study, data from Part B (Physician/Supplier) files from all beneficiaries with one or more claims for cataract surgery (CPT 66850, 66920, 66930, 66940, 66982, 66983, 66984) were initially reviewed. Diagnoses of endophthalmitis (International Classification of Diseases, Version 9, [ICD-9] 360.00, 360.01, 360.02, 360.03, 360.04, 360.19) were identified. From the endophthalmitis diagnosis date, claims were reviewed retrospectively to determine whether there was a cataract surgery in the 3 previous months. If there was a surgery, enrollment and claims data from the cataract surgery date were evaluated to ensure that the beneficiary remained covered for 6 months following the surgery date and that there were no additional cataract surgeries during this 6-month period. If the diagnosis of endophthalmitis for a given beneficiary did not meet these requirements, the beneficiary was retained in the data set and any additional diagnoses of endophthalmitis were evaluated in the same manner. One case of endophthalmitis meeting these requirements 
was identified, but the beneficiary was not evaluated again for additional diagnoses; each patient contributed only one observation. Beneficiaries who had a second cataract surgery during the 6-month follow-up were excluded from the analysis. The only exceptions to this were beneficiaries who appeared to have two surgeries on the same day or on two consecutive days, which is unlikely. In these cases, it was assumed that the second claim did not represent a true separate procedure but perhaps follow-up care related to the initial cataract surgery or a billing error. Only the first claim was included in cost analyses, but the beneficiaries were not excluded. There are cases of bilateral same-day surgery, but it was determined that this was unlikely in an elderly population. Beneficiaries who were included in the Medicare data prior to age 65 (for reasons such as renal failure) were excluded from the analysis. Beneficiaries with glaucoma (ICD 365) or age-related macular degeneration (ICD 362.5) during the observation period were also excluded from the analysis. Beneficiaries who had cataract surgery and developed endophthalmitis during the follow-up period ("cases") are compared to those who had cataract surgery but did not develop subsequent endophthalmitis ("controls").

Both claims (amounts billed by medical professionals or facilities) and reimbursements (amounts paid) coded for ophthalmic care (ICD 360-379) were included in the analysis. The mean claims and reimbursements over the 6-month observation period are presented in 2015 US dollars using the Bureau of Labor Statistics' Consumer Price Index for medical care commodities to inflate from the year in which the costs were collected. ${ }^{25}$ Rates of resource utilization between cases and controls are compared. Tables present differences in claims and payments, after adjusting for age, sex, race, and resident regions, between cases and controls, and the data are presented as a ratio (cost for cases divided by cost for controls).

Costs and frequency of selected ophthalmic diagnostic procedures (CPT 92015-92287) and ophthalmologist visits (CPT 92002-92014) were also evaluated. All data analysis was performed using SAS v9.4 (SAS Institute Inc., Cary, NC, USA).

\section{Results}

Table 1 presents demographic characteristics of the cases $(n=181)$ and controls $(n=153,679)$. Cases and controls were similar in terms of age and race, but cases were more likely to be male. Ophthalmic comorbid conditions of cases and controls are presented in Table 2 and were generally similar.
Table I Demographic characteristics of cataract patients

\begin{tabular}{|c|c|c|c|}
\hline & \multicolumn{2}{|l|}{ All beneficiaries } & \multirow[t]{2}{*}{$P$-value } \\
\hline & $\begin{array}{l}\text { Cases } \\
\text { (endophthalmitis } \\
\text { diagnosis) }\end{array}$ & Controls & \\
\hline $\bar{N}$ & 181 & 153,679 & - \\
\hline Gender, \% female & $49.7 \%$ & $59.6 \%$ & 0.007 \\
\hline Age (years) & & & 0.403 \\
\hline $65-69$ & $23.2 \%$ & $18.9 \%$ & \\
\hline $70-74$ & $22.1 \%$ & $28.0 \%$ & \\
\hline $75-79$ & $25.4 \%$ & $25.4 \%$ & \\
\hline $80-84$ & $21.5 \%$ & $18.4 \%$ & \\
\hline $85+$ & $7.7 \%$ & $9.4 \%$ & \\
\hline Race, $\%$ white & $84.0 \%$ & $88.7 \%$ & 0.079 \\
\hline
\end{tabular}

Cases were more likely to have disorders of the globe, as defined in Table 2.

Total claims and payments were consistently and significantly higher for cases than controls (Table 3). All patients had at least one Part B claim, with the majority also having claims for outpatient services or DME. Unadjusted differences in claims were $\$ 24,561$ while adjusted differences were slightly smaller at $\$ 23,120$. Overall total claims were $83 \%$ higher for cases compared with controls, although all types of Medicare services were significantly higher for cases. For both cases and controls, Part B was the most costly component, comprising $41 \%-46 \%$ of claims and payments, with outpatient next, comprising $20 \%-37 \%$ of expenditures.

Similarly, ophthalmic claims and payments were significantly different between cases and controls (Table 4). Less than one-third of controls had an outpatient ophthalmic claim in the 6-month window, while $>70 \%$ of cases had at least one outpatient ophthalmic claim. In almost all cases, claims were significantly higher for cases compared to controls. For ophthalmic care, the highest two categories of service were Part B and outpatient, which comprised $59 \%-76 \%$ and $24 \%-40 \%$ of the expenditures, respectively. Together, DME, home health care, hospice, inpatient, and skilled nursing were responsible for $<2 \%$ of ophthalmic expenditures.

Table 5 shows average number of claims and expenditures for specific ophthalmic services: diagnostic and ophthalmologist visits. In both groups, claims and payments were approximately twice as high for cases than for controls. Cases had significantly more diagnostic services (mean 2.2 versus 0.5 ) and ophthalmologist visits (mean 7.8 versus 1.8 ) than controls during the 6-month follow-up period (both $P<0.0001)$. 
Table 2 Concomitant ophthalmic conditions prior to cataract surgery

\begin{tabular}{|c|c|c|c|}
\hline \multirow[t]{3}{*}{ Condition (ICD-9-CM code) } & \multicolumn{3}{|l|}{ Frequency, \% } \\
\hline & \multicolumn{3}{|l|}{ All beneficiaries } \\
\hline & $\begin{array}{l}\text { Cases } \\
\text { (endophthalmitis } \\
\text { diagnosis) }\end{array}$ & $\begin{array}{l}\text { Controls } \\
\text { (no endophthalmitis } \\
\text { diagnosis) }\end{array}$ & Significance \\
\hline Retinal detachments and defects (36I) & 0.66 & 0.69 & 0.821 \\
\hline Diabetic retinopathy $(362.0)$ & 3.31 & 3.05 & 0.835 \\
\hline Retinal vascular occlusion (362.3) & 1.10 & 1.10 & 0.762 \\
\hline Uveitis (364.I-364.3) & 0.0 & 0.13 & 0.625 \\
\hline Disorders of vitreous body (379.2) & 12.15 & 10.40 & 0.440 \\
\hline Vision loss (369) & 1.10 & 0.81 & 0.656 \\
\hline Other disorders of globe (360.03 [chronic endophthalmitis], 360.04 & 2.21 & 0.24 & $<0.001$ \\
\hline \multicolumn{4}{|l|}{ [vitreous abscess], 360.1-360.4 [other endophthalmitis, degenerative } \\
\hline \multicolumn{4}{|l|}{ disorders of globe, hypotony of eye, degenerated conditions of globe], } \\
\hline \multicolumn{4}{|l|}{360.8 [other disorders of globe], 360.9 [unspecified disorder of globe])* } \\
\hline Other ophthalmic disorders (363 [chorioretinal inflammations], & 40.33 & 35.36 & 0.162 \\
\hline \multicolumn{4}{|l|}{364 [disorders of iris and ciliary body], 368 [visual disturbances], } \\
\hline \multicolumn{4}{|l|}{ 370-379 except 364.0-364.3 and 379.2 [keratitis, corneal opacity, disorders } \\
\hline \multicolumn{4}{|l|}{ of conjunctiva, inflammation of eyelids, other disorders of eyelids, disorders } \\
\hline of lacrimal system, disorders of orbit, disorders of optic nerve, strabismus])* & & & \\
\hline
\end{tabular}

Note: $* p<0.05$.

Abbreviation: ICD-9-CM, International Classification of Diseases, Version 9, Clinical Modification.

Table 3 Medicare claims (charges) and reimbursements (payments) for cataract patients - all medical care

\begin{tabular}{|c|c|c|c|c|c|c|c|c|c|c|}
\hline \multirow[t]{2}{*}{ Type } & \multicolumn{3}{|c|}{ Cases $(n=18 I)$} & \multicolumn{3}{|c|}{ Controls $(n=\mid 53,679)$} & \multicolumn{4}{|c|}{ Difference } \\
\hline & $\begin{array}{l}\text { \% with } \\
\text { claim }\end{array}$ & $\begin{array}{l}\text { Avg } \\
\text { Clm }\end{array}$ & $\begin{array}{l}\text { Avg } \\
\text { Pymt }\end{array}$ & $\begin{array}{l}\text { \% with } \\
\text { claim }\end{array}$ & $\begin{array}{l}\text { Avg } \\
\text { Clm }\end{array}$ & $\begin{array}{l}\text { Avg } \\
\text { Pymt }\end{array}$ & $\begin{array}{l}\text { Claim } \\
(\$)\end{array}$ & $\begin{array}{l}\text { Adjusted } \\
\text { claims - } \\
\text { ratio* }\end{array}$ & $\begin{array}{l}\text { Payment } \\
\text { (\$) }\end{array}$ & $\begin{array}{l}\text { Adjusted } \\
\text { payment - } \\
\text { ratio* }\end{array}$ \\
\hline Durable Medical Equipment & 49.7 & $\$ 699$ & $\$ 206$ & 52.4 & $\$ 559$ & $\$ 195$ & $\$ 140$ & 1.26 & $\$ 11$ & 1.06 \\
\hline Home Health Agency & 10.5 & $\$ 324$ & $\$ 425$ & 5.3 & $\$ 230$ & $\$ 233$ & $\$ 94$ & 1.41 & $\$ 192$ & 1.79 \\
\hline Hospice & 0.6 & $\$ 230$ & $\$ 143$ & 0.2 & $\$ 49$ & $\$ 30$ & $\$ 181$ & 4.70 & $\$ 113$ & 4.91 \\
\hline Inpatient & 15.5 & $\$ 8,071$ & $\$ 1,688$ & 10.1 & $\$ 6,346$ & $\$ 1,558$ & $\$ 1,725$ & 1.24 & $\$ 130$ & 1.06 \\
\hline Outpatient & 88.4 & $\$ 20,396$ & $\$ 3,008$ & 72.5 & $\$ 8,789$ & $\$ 1,309$ & $\$ 11,607$ & 2.23 & $\$ 1,699$ & 2.26 \\
\hline Part B & 100.0 & $\$ 22,050$ & $\$ 5,351$ & 100.0 & $\$ 11,558$ & $\$ 2,869$ & $\$ 10,492$ & 1.88 & $\$ 2,482$ & 1.85 \\
\hline Skilled Nursing Facility & 3.9 & $\$ 823$ & $\$ 729$ & 2.2 & $\$ 504$ & $\$ 295$ & $\$ 319$ & 1.68 & $\$ 434$ & 2.51 \\
\hline Total $^{\mathrm{a}}$ & 100.0 & $\$ 52,597$ & $\$ 1 \mid, 551$ & 100.0 & $\$ 28,036$ & $\$ 6,488$ & $\$ 24,561$ & 1.83 & $\$ 5,063$ & 1.76 \\
\hline
\end{tabular}

Notes: *Ratio $=$ cases/controls, significant at $P<0.000$ I unless indicated. ${ }^{2}$ Totals may not equal the sums of individual service categories claims/payments due to weighting reflecting different rates of use of services.

Table 4 Medicare claims (charges) and reimbursements (payments) for cataract patients - ophthalmic care

\begin{tabular}{|c|c|c|c|c|c|c|c|c|c|c|}
\hline \multirow[t]{2}{*}{ Type } & \multicolumn{3}{|c|}{ Cases $(n=181)$} & \multicolumn{3}{|c|}{ Controls $(n=153,679)$} & \multicolumn{4}{|c|}{ Difference } \\
\hline & $\begin{array}{l}\% \text { with } \\
\text { claim }\end{array}$ & $\begin{array}{l}\text { Avg } \\
\text { Clm }\end{array}$ & $\begin{array}{l}\text { Avg } \\
\text { Pymt }\end{array}$ & $\begin{array}{l}\text { \% with } \\
\text { claim }\end{array}$ & $\begin{array}{l}\text { Avg } \\
\text { Clm }\end{array}$ & $\begin{array}{l}\text { Avg } \\
\text { Pymt }\end{array}$ & $\begin{array}{l}\text { Claim } \\
(\$)\end{array}$ & $\begin{array}{l}\text { Adjusted } \\
\text { claims - } \\
\text { ratio* }\end{array}$ & $\begin{array}{l}\text { Payment } \\
\text { (\$) }\end{array}$ & $\begin{array}{l}\text { Adjusted } \\
\text { payment - } \\
\text { ratio* }\end{array}$ \\
\hline Durable Medical Equipment & 2.8 & $\$ 6$ & $\$ 3$ & 2.4 & $\$ 7$ & $\$ 2$ & $-\$ 1$ & $0.94 * *$ & $\$ 1$ & 1.58 \\
\hline Home Health Agency & 0.6 & $\$ 10$ & $\$ 15$ & 0.0 & $\$ 1$ & $\$ 1$ & $\$ 9$ & 11.30 & $\$ 14$ & 14.23 \\
\hline Hospice & 0.0 & $\$ 0$ & $\$ 0$ & 0.0 & $\$ 0$ & $\$ 0$ & $\$ 0$ & 1.00 & $\$ 0$ & I \\
\hline Inpatient & 1.1 & $\$ 106$ & $\$ 41$ & 0.0 & $\$ 5$ & $\$ 1$ & $\$ 101$ & 23.85 & $\$ 40$ & 39.67 \\
\hline Outpatient & 71.3 & $\$ 10,094$ & $\$ 1,553$ & 32.8 & $\$ 2,655$ & $\$ 461$ & $\$ 7,439$ & 3.77 & $\$ 1,092$ & 3.39 \\
\hline Part B & 100.0 & $\$ 14,730$ & $\$ 3,330$ & 100.0 & $\$ 6,443$ & $\$ 1,460$ & $\$ 8,287$ & 2.26 & $\$ 1,870$ & 2.26 \\
\hline Skilled Nursing Facility & 0.6 & $\$ 14$ & $\$ 10$ & 0.0 & $\$ 1$ & $\$ 0$ & $\$ 13$ & 40.16 & $\$ 10$ & 45.21 \\
\hline Total $^{\mathrm{a}}$ & 100.0 & $\$ 24,960$ & $\$ 4,952$ & 100.0 & $\$ 9,111$ & $\$ 1,925$ & $\$ 15,849$ & 2.71 & $\$ 3,027$ & 2.56 \\
\hline
\end{tabular}

Notes: $*$ Ratio $=$ cases/controls, significant at $P<0.000$ I unless indicated. **Significant at $P=0.0433$. ${ }^{a}$ Totals may not equal the sums of individual service categories claims/ payments due to weighting reflecting different rates of use of services. 
Table 5 Medicare claims (charges) and reimbursements (payments) for ophthalmic care for cataract patients - diagnostic services and ophthalmologist visits

\begin{tabular}{|c|c|c|}
\hline \multirow[t]{2}{*}{ Type } & $\begin{array}{l}\text { Cases } \\
(n=181)\end{array}$ & $\begin{array}{l}\text { Controls } \\
(n=\mid 53,679)\end{array}$ \\
\hline & $\begin{array}{l}\text { Number of claims } \\
\text { (mean, } 95 \% \mathrm{Cl} \text { ) }\end{array}$ & $\begin{array}{l}\text { Number of claims } \\
\text { (mean, } 95 \% \mathrm{Cl} \text { ) }\end{array}$ \\
\hline Diagnostic services*a & $2.2(2.0-2.5)$ & $0.5(0.5-0.5)$ \\
\hline Ophthalmologist visits ${ }^{*, a}$ & $7.8(7.4-8.2)$ & I.8 (I.8-I.8) \\
\hline
\end{tabular}

Notes: $* P<0.001$, cases versus controls, for number of claims, for differences in

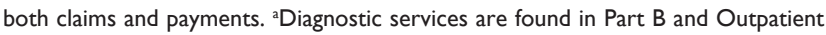
only. Ophthalmologist visits are found under Part B only.

Abbreviation: $\mathrm{Cl}$, confidence interval.

\section{Discussion}

This study evaluated rates of resource utilization and costs for individuals with endophthalmitis following cataract surgery. Diagnosis and treatment of endophthalmitis was associated with substantial increases in costs (both claims and reimbursements). These findings are consistent with previous studies, some of which even found substantial inpatient costs associated with endophthalmitis..$^{15,17}$

There may be patient characteristics that are associated with higher rates of endophthalmitis, and thus present an even stronger case for prophylaxis. For example, there are higher rates of post-cataract surgery endophthalmitis among men, older individuals, African-Americans, and Native Americans. ${ }^{26}$ Other factors that may be associated with endophthalmitis rates could not be explored with the data available in this study, including annual volume or years in practice of surgeons. ${ }^{26}$

Resource utilization and medical expenditures attributable to endophthalmitis are likely to persist beyond the period of observation in this study, although direct treatment costs are likely captured in this 6-month window, with the exception of any self-administered medications, which would not be included in the available Medicare claims data. For cases associated with permanent visual impairment, there may be long-term increases in health care resource utilization and costs. This can include longer length of inpatient admissions,${ }^{27}$ higher rates of falls and injuries, ${ }^{28}$ as well as costs associated with home health care and caregiving. ${ }^{29}$ Although not directly related to endophthalmitis, these events and costs are certainly indirect results of the condition. Our previous analysis found annual ophthalmic costs of $\$ 3,464$ ( $\$ 4,780$ when inflated to 2015 US dollars $)^{17}$ while the costs using more recent data were $\$ 3,002$ over a 6 -month period. Analyses in this study did not identify when cases occurred during the observation period; a recent study ${ }^{26}$ on endophthalmitis led us to limit the time period to 6 months.
The rate was found to be 1.2 endophthalmitis cases per 1,000 surgeries, which is similar to other findings that have identified rates of $0.63-1.6$ cases per 1,000 surgeries. ${ }^{6,26,30,31}$ As Gower et al point out, ${ }^{31}$ differences in the definition of cases influence some of this variation; however, rates have been fairly stable over time, even with a number of clinical and epidemiologic trends. For example, patients and their clinical characteristics and previous exposures as well as type of incision, lens, anesthesia, and setting have changed over time. ${ }^{32-35}$ Increased use of anti-VEGF injections ${ }^{12}$ and glaucoma filtering surgery ${ }^{35}$ may also be associated with increased risk.

There are certain limitations of this study based on the claims database selected for analysis. Although the Medicare claims data are arguably the largest collection of cataract surgery data in the United States, the database was designed for billing and administrative purposes rather than clinical. The lack of clinical indicators combined with the fact that intraoperative prophylactic medication use would be included in reimbursement rather than separately raising challenges. Thus, it is not possible to know how many patients received prophylactic antibiotics, as eye drops provided during surgery would not have been reported as a separate claim. For the cost analysis, patients with AMD who may have been treated with anti-VEGF injections were excluded; it is possible that both rates of endophthalmitis and average costs might be higher for this subset of patients, meaning that the estimates found in this study may be low.

By requiring a period free of other cataract surgeries and including only patients with a single surgery during the follow-up period, the study tried to increase the likelihood that the endophthalmitis was associated with the index event (ie, the cataract surgery). This analysis excluded patients who seemed to have same day or next-day surgery, yet this may have eliminated some valid procedures. For patients with lower risk, performing bilateral procedures in quick succession is becoming more common ${ }^{36}$ and may minimize the need for a second approval for physical or interim corrective eyewear. The costs identified in this study reflect only direct medical costs from the perspective of Medicare. Out of pocket costs associated with immediate endophthalmitis care, including transportation and caregiver assistance, are not quantified, nor are longer-term use of these services or the rental or purchase of vision aids. ${ }^{11}$ The exclusion of these other types of costs and services reinforces that this analysis of direct medical costs is a conservative estimate of the burden of the condition. By examining the differences in all ophthalmic costs and not just those coded for endophthalmitis, this analysis attempted to capture claims that may not have included endophthalmitis as a diagnosis code but may 
have been affected by the patient's infection. The authors tried to limit the other ophthalmic conditions that could contribute to this cost by excluding patients with selected comorbidities. This "clean" population of endophthalmitis patients might have lower costs than patients with existing comorbidities or recent surgeries. However, this approach of looking only at ophthalmic claims still likely excludes some costs associated with the consequences of vision loss such as anxiety, depression, injuries or falls, and increased inpatient length of stay for nonophthalmic diagnoses. The estimate from this study should be considered a conservative assessment of endophthalmitis costs.

The impact of visual impairment on quality of life is well-documented. ${ }^{37-40}$ The nature of claims analysis prevents us from being able to make assessments about cost per quality-adjusted life-year, although it does allow for better cost estimates than would be possible in most prospective study settings.

The rate of endophthalmitis has remained steady over time, suggesting the use of antibiotic prophylaxis has been an important prevention protocol. ${ }^{18,19,21,41}$ Studies that have empirically explored costs associated with prophylactic antibiotic treatment have consistently identified benefits, although most of these studies and cost analyses were conducted outside the United States. ${ }^{21,42,43}$ Perhaps the most challenging aspect of understanding the effectiveness of antibiotic prophylaxis is that, as Gower et al point out, ${ }^{44}$ few studies have been powered sufficiently to detect differences in this fairly uncommon infection. Rates of endophthalmitis have been shown to decrease significantly with the use of antibiotic prophylaxis although there remains a range across studies, likely partly attributable to variation in patient characteristics and risk factors. ${ }^{45}$ Rates have decreased from $0.31 \%-1.24 \%$ to as low as $0.01 \%-0.08 \%$ with intracameral cefuroxime use. ${ }^{46}$ Studies that have considered cost-effectiveness in other countries suggest that prophylaxis may be cost-effective. ${ }^{21,47}$ The low cost associated with a topical antibiotic administered before and/or after surgery, which may be decreasing as products that do not require compounding become available, ${ }^{48}$ may be a reasonable trade-off for avoiding the substantial costs associated with postoperative endophthalmitis in a United States Medicare population..$^{21,47}$

\section{Disclosure}

Exponent, the employer of authors JKS, CKH, and ECL, received a grant from Alcon Laboratories to conduct this research. DWC is employed by Alcon Research, Ltd. The sponsor or funding organization participated in the design of the study, interpretation of the data, preparation, and review/approval of the manuscript. The authors report no other conflicts of interest in this work.

\section{References}

1. Schein OD, Cassard SD, Tielsch JM, Gower EW. Cataract surgery among Medicare beneficiaries. Ophthalmic Epidemiol. 2012;19(5):257-264.

2. Brown GC, Brown MM, Menezes A, Busbee BG, Lieske HB, Lieske PA. Cataract surgery cost utility revisited in 2012: a new economic paradigm. Ophthalmology. 2013;120(12):2367-2376.

3. Groessl EJ, Liu L, Sklar M, Tally SR, Kaplan RM, Ganiats TG. Measuring the impact of cataract surgery on generic and vision-specific quality of life. Qual Life Res. 2013;22(6):1405-1414.

4. Fraser ML, Meuleners LB, Lee AH, Ng JQ, Morlet N. Vision, quality of life and depressive symptoms after first eye cataract surgery. Psychogeriatrics. 2013;13(4):237-243.

5. Coleman AL. How Big Data informs us about cataract surgery: The LXXII Edward Jackson Memorial Lecture. Am J Ophthalmol. 2015;160(6):1090-1103.e3.

6. Stein JD, Grossman DS, Mundy KM, Sugar A, Sloan FA. Severe adverse events after cataract surgery among Medicare beneficiaries. Ophthalmology. 2011;118(9):1716-1723.

7. Spadea L. Treatment of postoperative endophthalmitis. US Ophthalmic Rev. 2014;7(2):146-153.

8. Lalitha P, Rajagopalan J, Prakash K, Ramasamy K, Prajna NV, Srinivasan M. Postcataract endophthalmitis in South India incidence and outcome. Ophthalmology. 2005;112(11):1884-1889.

9. Miller JJ, Scott IU, Flynn HW Jr, Smiddy WE, Corey RP, Miller D. Endophthalmitis caused by Streptococcus pneumoniae. Am J Ophthalmol. 2004;138(2):231-236.

10. Miller JJ, Scott IU, Flynn HW Jr, Smiddy WE, Newton J, Miller D. Acute-onset endophthalmitis after cataract surgery (2000-2004): incidence, clinical settings, and visual acuity outcomes after treatment. Am J Ophthalmol. 2005;139(6):983-987.

11. Dossarps D, Bron AM, Koehrer P, Aho-Glele LS, Creuzot-Garcher C. FReCh Retinal Specialists net. Endophthalmitis after intravitreal injections: Incidence, presentation, management, and visual outcome. Am J Ophthalmol. 2015;160(1):17-25.

12. Hahn P, Yashkin AP, Sloan FA. Effect of prior anti-VEGF injections on the risk of retained lens fragments and endophthalmitis after cataract surgery in the elderly. Ophthalmology. 2016;123(2):309-315.

13. The Endophthalmitis Vitrectomy Study Group. Results of the endophthalmitis vitrectomy study. Arch Ophthalmol. 1995;113:1479-1496.

14. Chang DF, Braga-Mele R, Henderson BA, Mamalis N, Vasavada A. Antibiotic prophylaxis of postoperative endophthalmitis after cataract surgery: results of the 2014 ASCRS member survey. $J$ Cataract Refract Surg. 2015;41(6):1300-1305.

15. Fongsre T, Aiempanakit K, Ratanalerdwee T, Leelaprasasne S, KanokKantapong S, Jamulitrat S. Extra charge and extra length of hospital stay attributable to postcataract surgery endophthalmitis. Am J Infect Control. 2004;32(6):374-375.

16. Sulkes DJ, Scott IU, Flynn HW Jr, Feuer WJ. Evaluating outpatient versus inpatient costs in endophthalmitis management. Retina. 2002; 22(6):747-751.

17. Schmier JK, Halpern MT, Covert DW, Lau EC, Robin AL. Evaluation of Medicare costs of endophthalmitis among patients after cataract surgery. Ophthalmology. 2007;114(6):1094-1099.

18. Barry P, Seal DV, Gettinby G, Lees F, Peterson M, Revie CW. ESCRS study of prophylaxis of postoperative endophthalmitis after cataract surgery: preliminary report of principal results from a European multicenter study. J Cataract Refract Surg. 2006;32(3):407-410.

19. Seal DV, Barry P, Gettinby G, et al. ESCRS study of prophylaxis of postoperative endophthalmitis after cataract surgery: case for a European multicenter study. J Cataract Refract Surg. 2006;32(3):396-406.

20. American Academy of Ophthalmology. Cataract in the Adult Eye. San Francisco (CA): American Academy of Ophthalmology; 2001. 
21. Linertova R, Abreu-Gonzalez R, Garcia-Perez L, et al. Intracameral cefuroxime and moxifloxacin used as endophthalmitis prophylaxis after cataract surgery: systematic review of effectiveness and costeffectiveness. Clin Ophthalmol. 2014;8:1515-1522.

22. Rodriguez-Caravaca G, Garcia-Saenz MC, Villar-Del-Campo MC, Andres-Alba Y, Arias-Puente A. Incidence of endophthalmitis and impact of prophylaxis with cefuroxime on cataract surgery. J Cataract Refract Surg. 2013;39(9):1399-1403.

23. Sharifi E, Porco TC, Naseri A. Cost-effectiveness analysis of intracameral cefuroxime use for prophylaxis of endophthalmitis after cataract surgery. Ophthalmology. 2009;116(10):1887-1896.e1881.

24. Gollogly HE, Hodge DO, St Sauver JL, Erie JC. Increasing incidence of cataract surgery: population-based study. J Cataract Refract Surg. 2013; 39(9):1383-1389.

25. Bureau of Labor Statistics. Consumer Price Index - All Urban Consumers. August 3, 2005. Available from: http://www.bls.gov/cpi/ cpid1512.pdf. Accessed Feb 1, 2016.

26. Keay L, Gower EW, Cassard SD, Tielsch JM, Schein OD. Postcataract surgery endophthalmitis in the United States: analysis of the complete 2003 to 2004 Medicare database of cataract surgeries. Ophthalmology. 2012;119(5):914-922.

27. Morse AR, Yatzkan E, Berberich B, Arons RR. Acute care hospital utilization by patients with visual impairment. Arch Ophthalmol. 1999; 117(7):943-949

28. Scuffham $P$, Chaplin S, Legood R. Incidence and costs of unintentional falls in older people in the United Kingdom. J Epidemiol Community Health. 2003;57(9):740-744.

29. Frick KD, Gower EW, Kempen JH, Wolff JL. Economic impact of visual impairment and blindness in the United States. Arch Ophthalmol. 2007; 125(4):544-550.

30. Du DT, Wagoner A, Barone SB, et al. Incidence of endophthalmitis after corneal transplant or cataract surgery in a medicare population. Ophthalmology. 2014;121(1):290-298.

31. Gower EW, Keay LJ, Stare DE, et al. Characteristics of endophthalmitis after cataract surgery in the United States Medicare population. Ophthalmology. 2015;122(8):1625-1632.

32. Soltau JB, Rothman RF, Budenz DL, et al. Risk factors for glaucoma filtering bleb infections. Arch Ophthalmol. 2000;118(3):338-342.

33. Taban M, Behrens A, Newcomb RL, et al. Acute endophthalmitis following cataract surgery: a systematic review of the literature. Arch Ophthalmol. 2005;123(5):613-620.

34. Cao H, Zhang L, Li L, Lo S. Risk factors for acute endophthalmitis following cataract surgery: a systematic review and meta-analysis. PLoS One. 2013;8(8):e71731.

35. Jampel HD, Quigley HA, Kerrigan-Baumrind LA, Melia BM, Friedman D, Barron Y. Risk factors for late-onset infection following glaucoma filtration surgery. Arch Ophthalmol. 2001;119(7):1001-1008.
36. Bethke W. Is bilateral, same-day cataract the future? Rev Ophthalmol. 2015. Available from: http://www.reviewofophthalmology.com/ content/d/cover_story/c/54144/

37. Vu HT, Keeffe JE, McCarty CA, Taylor HR. Impact of unilateral and bilateral vision loss on quality of life. Br J Ophthalmol. 2005;89(3): 360-363.

38. Chia EM, Mitchell P, Rochtchina E, Foran S, Wang JJ. Unilateral visual impairment and health related quality of life: the Blue Mountains Eye Study. Br J Ophthalmol. 2003;87(4):392-395.

39. Sharma S, Brown GC, Brown MM, et al. Converting visual acuity to utilities. Can J Ophthalmol. 2000;35(5):267-272.

40. Brown GC. Vision and quality-of-life. Trans Am Ophthalmol Soc. 1999; 97:473-511

41. Garcia-Saenz MC, Arias-Puente A, Rodriguez-Caravaca G, Banuelos JB. Effectiveness of intracameral cefuroxime in preventing endophthalmitis after cataract surgery: ten-year comparative study. J Cataract Refract Surg. 2010;36(2):203-207.

42. Krummenauer F, Kurz S, Dick HB. Epidemiological and health economical evaluation of intraoperative antibiosis as a protective agent against endophthalmitis after cataract surgery. Eur J Med Res. 2005; 10(2):71-75

43. Haripriya A, Chang DF, Namburar S, Smita A, Ravindran RD. Efficacy of intracameral moxifloxacin endophthalmitis prophylaxis at Aravind Eye Hospital. Ophthalmology. 2016;123(2):302-308.

44. Gower EW, Lindsley K, Nanji AA, Leyngold I, McDonnell PJ. Perioperative antibiotics for prevention of acute endophthalmitis after cataract surgery. Cochrane Database Syst Rev. 2013;(7):CD006364.

45. Hashemian H, Mirshahi R, Khodaparast M, Jabbarvand M. Post-cataract surgery endophthalmitis: brief literature review. J Curr Ophthalmol. 2016;28(3):101-105.

46. Barry P, Cordoves L, Gardner S. ESCRS Guidelines for Prevention and Treatment of Endophthalmitis Following Cataract Surgery: Data, Dilemmas and Conclusions. Dublin, Ireland: European Society of Cataract and Refractive Surgeons; 2013. Available from: http://escrs. org/downloads/Endophthalmitis-Guidelines.pdf

47. Au CP, White AJ, Healey PR. Efficacy and cost-effectiveness of intracameral vancomycin in reducing postoperative endophthalmitis incidence in Australia. Clin Exp Ophthalmol. Epub 2016 Jun 17.

48. Purslow C, Davey K, Johnson M, Pietri G, Suri G. Budget impact assessment of Aprokam(R) compared with unlicensed cefuroxime for prophylaxis of post-cataract surgery endophthalmitis. BMC Ophthalmol. $2015 ; 15: 72$.
Clinical Ophthalmology

\section{Publish your work in this journal}

Clinical Ophthalmology is an international, peer-reviewed journa covering all subspecialties within ophthalmology. Key topics include: Optometry; Visual science; Pharmacology and drug therapy in eye diseases; Basic Sciences; Primary and Secondary eye care; Patient Safety and Quality of Care Improvements. This journal is indexed on Submit your manuscript here: http://www.dovepress.com/clinical-ophthalmology-journa

\section{Dovepress}

PubMed Central and CAS, and is the official journal of The Society of Clinical Ophthalmology (SCO). The manuscript management system is completely online and includes a very quick and fair peer-review system, which is all easy to use. Visit http://www.dovepress.com/ testimonials.php to read real quotes from published authors. 